\title{
5-Azido-4-dimethylamino-1-methyl-1,2,4-triazolium Hexafluoridophosphate and Derivatives
}

\author{
Gerhard Laus ${ }^{1, *}$, Volker Kahlenberg ${ }^{2}$ and Herwig Schottenberger ${ }^{1}$ \\ 1 Faculty of Chemistry and Pharmacy, University of Innsbruck, 6020 Innsbruck, Austria; \\ herwig.schottenberger@uibk.ac.at \\ 2 Institute of Mineralogy and Petrography, University of Innsbruck, 6020 Innsbruck, Austria; \\ volker.kahlenberg@uibk.ac.at \\ * Correspondence: gerhard.laus@uibk.ac.at; Tel.: +43-512-507-57080; Fax: +43-512-507-57099 \\ Academic Editor: Helmut Cölfen
}

Received: 14 January 2016; Accepted: 2 February 2016; Published: 5 February 2016

\begin{abstract}
Azido-4-(dimethylamino)-1-methyl-1,2,4-triazolium hexafluoridophosphate was synthesized from the corresponding 5-bromo compound with $\mathrm{NaN}_{3}$. Reaction with bicyclo[2.2.1]hept-2-ene yielded a tricyclic aziridine, addition of an $\mathrm{N}$-heterocyclic carbene resulted in a triazatrimethine cyanine, and reduction with triphenylphosphane gave the 5-amino derivative. The crystal structures of three nitrogen-rich salts were determined. Thermoanalysis of the cationic azide and triazene showed exothermal decomposition. The triazene exhibited negative solvatochromism in polar solvents involving the dipolarity $\pi^{*}$ and hydrogen-bond donor acidity $\alpha$ of the solvent.
\end{abstract}

Keywords: azide; aziridine; cyanine; solvatochromism; thermoanalysis; triazene; triazole

\section{Introduction}

Azidoazoles, in particular azidotetrazoles [1-3] and azidotriazoles [4-6], are fine examples of "nitrogen-rich" materials. Reports on quaternary azidoazolium cations are more limited (benzimidazole, thiazole [7-9]). A 1,4-disubstituted 1,2,4-triazolium salt bearing an azide group at the less reactive 3-position was described [10]. Crystal structures of only one 1,3-disubstituted 2-azidoimidazolium salt [11] and one 1,3-disubstituted 2-azidoimidazolinium salt [12] are known. Organic azides were occasionally converted to triazenes, essentially by reaction with $N$-heterocyclic carbenes. Thus, a number of crystal structures of neutral aryl or alkyl triazenes have been reported [13-20]. The use of quaternary azidoazolium cations for this transformation resulted in cationic triazatrimethine cyanine dyes, but only one crystal structure of this type was reported, although with benzimidazole [21]. Until now azidotriazolium salts primarily received attention as energetic compounds but their reactions have been rarely examined. We tentatively explored some reactions of a new 1,4-disubstituted 5-azido-1,2,4-triazolium salt. Here we report the crystal structures of this reactive azide and two of its derivatives.

\section{Results and Discussion}

The title compound 1 was synthesized from the corresponding bromo compound and sodium azide (Figure 1) by analogy with a similar imidazolium salt [11]. The well-known versatility of azide chemistry [22] motivated us to attempt exemplary reactions of $\mathbf{1}$. Thus, dipolar cycloaddition of azides with alkenes is known to produce 1,2,3-triazolines or aziridines [23]. In our hands, strained bicycloheptene (norbornene) [24,25] reacted with azidotriazolium salt 1 to give the tricyclic aziridine 2 in acceptable yield. 
<smiles></smiles>

1<smiles></smiles>

1

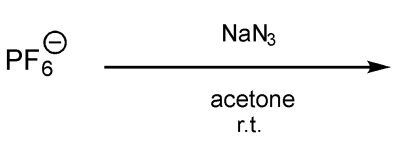

$\mathrm{PF}_{6}^{\ominus}$

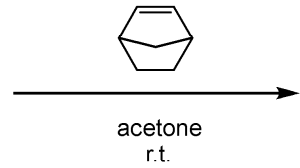

r.t.
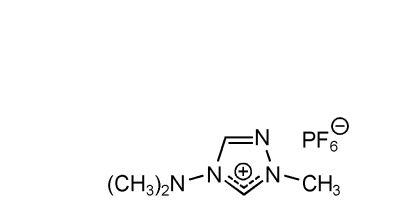

$\mathrm{PF}_{6}^{\ominus}$

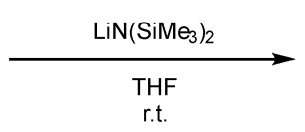<smiles></smiles>

1<smiles></smiles>

$\mathrm{PF}_{6}^{\ominus}$<smiles>C1CC2CC1C1NC21</smiles>

2<smiles></smiles>

3<smiles></smiles>

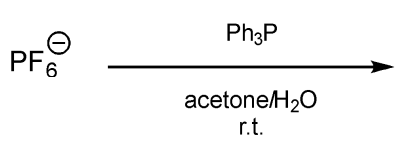<smiles></smiles><smiles>[Po]</smiles>

4

Figure 1. Reagents and conditions: (a) $\mathrm{NaN}_{3}$, acetone, rt; (b) bicyclo[2.2.1]hept-2-ene, acetone, rt; (c) 4-(dimethylamino)-1-methyl-1,2,4-triazolium $\mathrm{PF}_{6}, \mathrm{LiN}\left(\mathrm{SiMe}_{3}\right)_{2}, \mathrm{THF}, \mathrm{rt}$; (d) $\mathrm{Ph}_{3} \mathrm{P}$, acetone, $\mathrm{H}_{2} \mathrm{O}$, rt.

Recently, "click chemistry" (Cu-catalyzed cycloaddition of azide and alkyne) was successful with 2-azido-1-methylimidazole [26], but not with quaternary 2-azidoimidazolium salts, which can be explained by electron-deficiency of the cationic azide. Attempts to add phenylethyne to 1 were also not met with success, possibly due to the same reason.

Reaction of azide 1 with the carbene derived from the correspondimg triazolium salt resulted in the formation of triazene 3 in modest yield. Staudinger reduction of the azide $\mathbf{1}$ with triphenylphosphane led to the 5-amino compound 4 . The progress of this transformation could be visually followed as the mixture turned yellow (formation of triazene), molecular nitrogen gas was evolved, and the colour disappeared again (formation of iminophosphorane). The product was obtained after final hydrolysis.

The hexafluoridophophate was chosen as an advantageous anion because these salts crystallize readily and are non-hygroscopic. The role of fluorine in crystal structures of organic compounds has been reviewed [27]. It has been concluded that short C-H...F contacts between oppositely charged molecules are genuine interionic hydrogen bonds [28]. On the other hand, these interactions are weak enough to escape the undesirable formation of distracting aggregates, thus allowing to concentrate on the geometry of the cation. Crystal data and refinement details are summarized in Table 1. Selected bond lengths and angles are collected in Table 2. Hydrogen bond geometries are outlined in Table 3. 
Table 1. Crystal data and structure refinement details for compounds 1-3.

\begin{tabular}{|c|c|c|c|}
\hline Compound & 1 & 2 & 3 \\
\hline CCDC No. & 1444906 & 1444907 & 1444908 \\
\hline Empirical formula & $\mathrm{C}_{5} \mathrm{H}_{10} \mathrm{~N}_{7} \cdot \mathrm{F}_{6} \mathrm{P}$ & $\mathrm{C}_{12} \mathrm{H}_{20} \mathrm{~N}_{5} \cdot \mathrm{F}_{6} \mathrm{P}$ & $\mathrm{C}_{10} \mathrm{H}_{20} \mathrm{~N}_{11} \cdot \mathrm{F}_{6} \mathrm{P}$ \\
\hline Formula weight & 313.17 & 379.30 & 439.34 \\
\hline Crystal system & Monoclinic & Orthorhombic & Monoclinic \\
\hline Space group & $P 22_{1} / n$ & Pnma & $P 2_{1} / n$ \\
\hline$a / \AA$ & $7.6592(2)$ & $16.8383(3)$ & $9.6566(6)$ \\
\hline$b / \AA$ & $11.3231(4)$ & $8.6698(2)$ & $18.3957(8)$ \\
\hline$c / \AA$ & $13.9886(4)$ & $11.6179(2)$ & $11.6647(7)$ \\
\hline$\beta /{ }^{\circ}$ & $101.275(3)$ & & $113.308(7)$ \\
\hline Volume $/ \AA^{3}$ & $1189.76(6)$ & $1696.04(6)$ & $1903.0(2)$ \\
\hline$Z$ & 4 & 4 & 4 \\
\hline$D_{\mathrm{x}} / \mathrm{g} \cdot \mathrm{cm}^{-3}$ & 1.75 & 1.49 & 1.53 \\
\hline$\mu / \mathrm{mm}^{-1}$ & 0.31 & 2.08 & 0.22 \\
\hline$F(000)$ & 632 & 784 & 904 \\
\hline Radiation & $\operatorname{MoK} \alpha$ & $\mathrm{CuK \alpha}$ & $\operatorname{MoK} \alpha$ \\
\hline Crystal size $/ \mathrm{mm}^{3}$ & $0.40 \times 0.40 \times 0.40$ & $0.40 \times 0.28 \times 0.24$ & $0.39 \times 0.12 \times 0.09$ \\
\hline$\theta_{\max } 1^{\circ}$ & 25.4 & 67.4 & 25.4 \\
\hline Index ranges & $\begin{array}{c}-9 \leqslant h \leqslant 9 \\
-13 \leqslant k \leqslant 12 \\
-14 \leqslant l \leqslant 16\end{array}$ & $\begin{array}{l}-19 \leqslant h \leqslant 20 \\
-10 \leqslant k \leqslant 10 \\
-13 \leqslant l \leqslant 13\end{array}$ & $\begin{array}{l}-11 \leqslant h \leqslant 11 \\
-21 \leqslant k \leqslant 21 \\
-12 \leqslant l \leqslant 14\end{array}$ \\
\hline Reflections collected & 7844 & 9779 & 10926 \\
\hline Independent reflections $\left(R_{\text {int }}\right)$ & $2185(0.023)$ & $1630(0.033)$ & $3452(0.032)$ \\
\hline Observed reflections $[I \geqslant 2 \sigma(I)]$ & 1777 & 1523 & 2845 \\
\hline Restraints/parameters & $0 / 176$ & $0 / 195$ & $57 / 307$ \\
\hline Goodness-of-fit on $F^{2}$ & 1.09 & 1.07 & 1.01 \\
\hline$R_{1}, w R_{2}[I>2 \sigma(I)]$ & $0.027,0.067$ & $0.058,0.158$ & $0.049,0.122$ \\
\hline$R_{1}, w R_{2}$ (all data) & $0.034,0.068$ & $0.061,0.161$ & $0.060,0.130$ \\
\hline Largest diff. peak and hole $/ \mathrm{e} \cdot \AA^{-3}$ & $0.19,-0.30$ & $0.30,-0.26$ & $0.44,-0.32$ \\
\hline
\end{tabular}

Table 2. Selected bond lengths, angles, and torsions for compounds $\mathbf{1}$ and $\mathbf{3}\left(\AA \mathrm{A}^{\circ}\right)$.

\begin{tabular}{ccc}
\hline & $\mathbf{1}$ & $\mathbf{3}$ \\
\hline C1-N5 & $1.367(2)$ & $1.357(3)$ \\
N5-N6 & $1.255(2)$ & $1.303(3)$ \\
N6-N7 & $1.118(29)$ & $1.302(3)$ \\
N7-C6 & & $1.352(4)$ \\
\hline C1-N5-N6 & $116.6(1)$ & $112.7(2)$ \\
N5-N6-N7 & $168.8(2)$ & $109.8(2)$ \\
N6-N7-C6 & & $114.0(2)$ \\
\hline C1-N5-N6-N7 & $171.9(8)$ & $176.8(2)$ \\
N5-N6-N7-C6 & & $178.4(2)$ \\
\hline
\end{tabular}


Table 3. C-H...F interactions in compounds 1-3 $\left(\AA,^{\circ}\right)$.

\begin{tabular}{|c|c|c|c|c|c|}
\hline Compound & Interaction & H...F & C...F & C-H...F & Symmetry Operation F \\
\hline \multirow{4}{*}{1} & C2-H...F1 & 2.329 & $3.263(2)$ & 167.7 & $x, y, z$ \\
\hline & C2-H...F2 & 2.399 & $3.133(2)$ & 133.9 & $x, y, z$ \\
\hline & $\mathrm{C} 5-\mathrm{H}_{\mathrm{C}} \ldots \mathrm{F} 4$ & 2.468 & $3.416(2)$ & 162.8 & $1+x, y, z$ \\
\hline & $\mathrm{C} 3-\mathrm{H}_{\mathrm{A}} \ldots \mathrm{F} 4$ & 2.530 & $3.425(2)$ & 151.8 & $1 / 2+x, 3 / 2-y,-1 / 2+z$ \\
\hline \multirow{4}{*}{2} & C2-H...F3 & 2.383 & 3.281 & 157.4 & $-1 / 2+x, 1 / 2-y, 3 / 2-z$ \\
\hline & $\mathrm{C} 4-\mathrm{H}_{\mathrm{A}} \ldots \mathrm{F} 2$ & 2.298 & $3.227(7)$ & 158.0 & $1 / 2-x,-1 / 2+y,-1 / 2+z$ \\
\hline & C10-H...F1 & 2.396 & $3.206(6)$ & 137.5 & $x, y, z$ \\
\hline & C6-H...F1 & 2.458 & $3.397(5)$ & 156.5 & $1 / 2-x, 1 / 2+y,-1 / 2+z$ \\
\hline \multirow{4}{*}{3} & C7-H...F4 & 2.283 & $3.15(1)$ & 152.0 & $1-x,-y, 1-z$ \\
\hline & C2-H...F1 & 2.298 & $3.16(1)$ & 151.0 & $3 / 2-x, 1 / 2+y, 3 / 2-z$ \\
\hline & $\mathrm{C} 5-\mathrm{H}_{\mathrm{C}} \ldots \mathrm{F} 3$ & 2.432 & $3.211(5)$ & 136.2 & $3 / 2-x, 1 / 2+y, 3 / 2-z$ \\
\hline & C9-H & 2.523 & $3.485(5)$ & 167.1 & $x, y, 1+z$ \\
\hline
\end{tabular}

\subsection{Crystal Structures}

The $\mathrm{C}_{5} \mathrm{H}_{10} \mathrm{~N}_{7}{ }^{+}$cation contains 58.3 wt.\% nitrogen and, thus, can be considered to be "nitrogen-rich". The azide group in $\mathbf{1}$ deviates considerably from linearity with an N5-N6-N7 angle of $168.8(2)^{\circ}$, it is rotated out of the ring plane by $26.4^{\circ}$ (Figure 2a), likely due to a repelling interaction between a lone electron pair on the $\mathrm{N}$ atom and the ring $\pi$ system. The heteroaromatic $\mathrm{C} 2-\mathrm{H}$ donates bifurcated hydrogen bonds to F1 and F2, whereas $\mathrm{H}$ atoms of two methyl groups form contacts to F4 (Figure 2b).

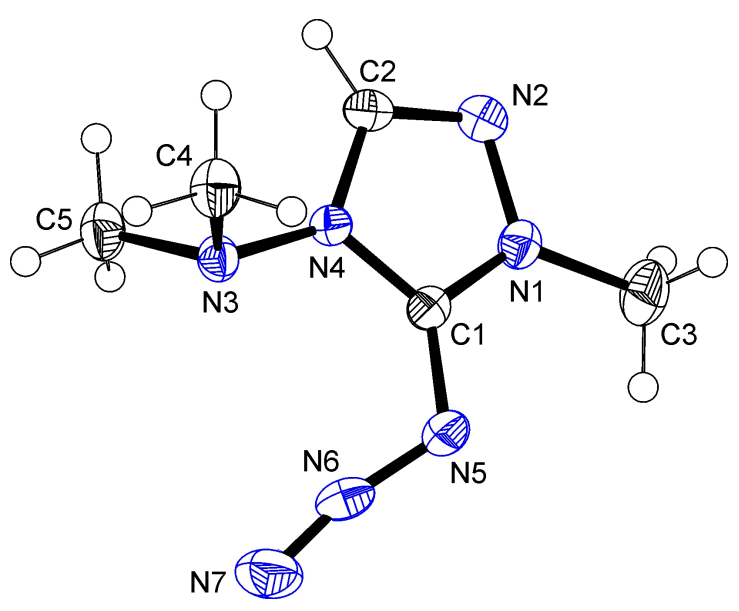

(a)

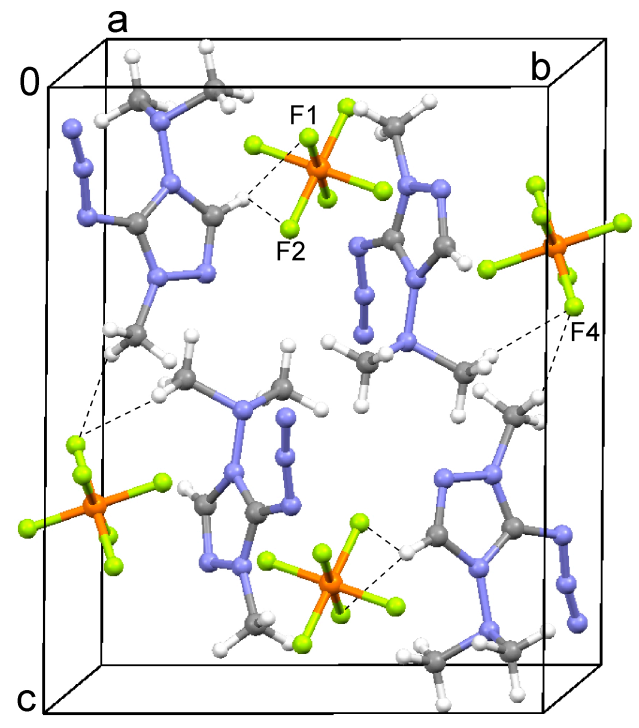

(b)

Figure 2. (a) ORTEP plot of the cation in 1; and (b) packing in the crystal structure of $\mathbf{1}$.

In the crystal structure of aziridine 2, the asymmetric unit contained half a formula unit. The triazole rings were located in the crystallographic mirror plane, whereas the $\mathrm{C} 4$ methyl groups are situated out of this plane. The C3 methyl group was found to be disordered over two orientations related by mirror symmetry. Part of the cation showed a 1:1 positional disorder by a crystallographic mirror plane. In the tricyclic group including N5, only C7 lay exactly in the mirror plane. All other atoms of this group were refined in general positions with occupancies of 0.5 (Figure 3a, only one disorder component shown). 


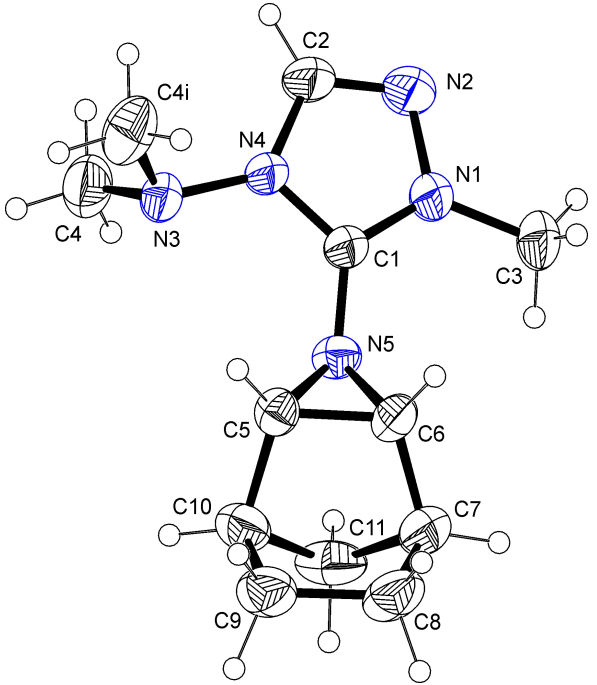

(a)

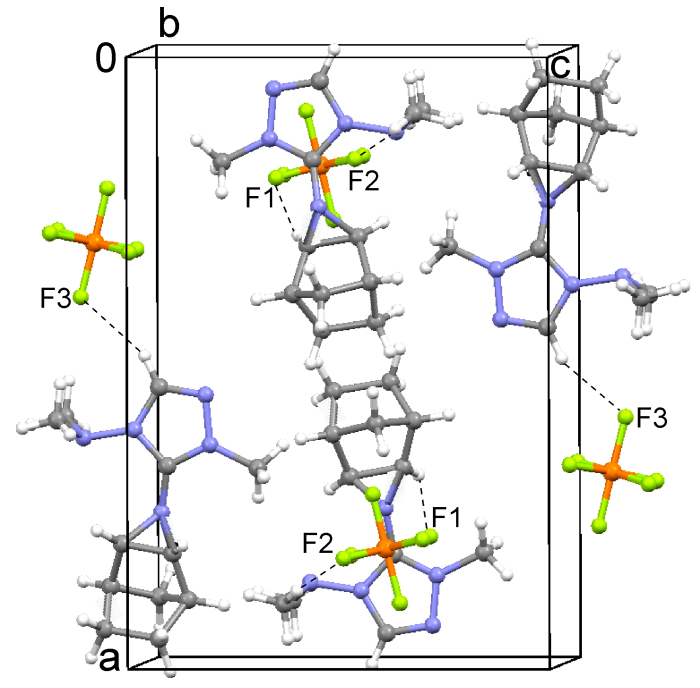

(b)

Figure 3. (a) ORTEP plot of the cation in 2; (b) Packing and C-H...F interactions in the crystal structure of 2. Symmetry operation i: $x, 1 / 2-y, z$.

A positional disorder of the $\mathrm{PF}_{6}$ anion with ratio 7:3 (ratio refined as free variable) was observed. Again, the heteroaromatic $\mathrm{C} 2-\mathrm{H}$ donates a hydrogen bond to $\mathrm{F} 3$, and aliphatic hydrogen atoms form contacts to F1 and F2 (Figure 3b).

The triazole-substituted triazene system in 3 is almost planar. The dihedral angle between the triazole rings is only $9.3^{\circ}$. The N5-N6 bond is twisted out of the plane of the adjacent triazole ring by $17.2^{\circ}$, and the N7-N6 bond out of the plane of the second triazole ring by $14.6^{\circ}$ (Figure 4a). Several $\mathrm{C}-\mathrm{H}$...F interactions involve the heteroaromatic $\mathrm{C} 2-\mathrm{H}$ and $\mathrm{C} 7-\mathrm{H}$, as well as the $\mathrm{C} 5$ and $\mathrm{C} 9$ methyl groups. Additionally, a C5-H...N5 interaction is observed (Figure 4b).

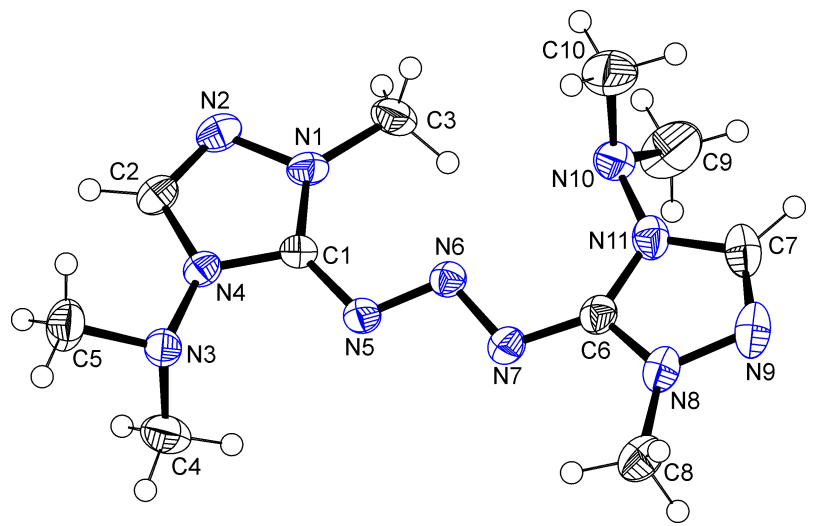

(a)

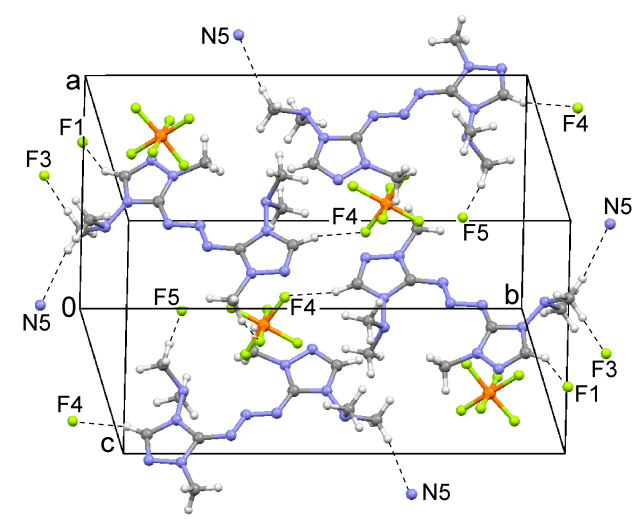

(b)

Figure 4. (a) ORTEP plot of the cation in 3. (b) Packing in the crystal structure of 3.

\subsection{UV Spectroscopy}

Compound 3 exhibited negative solvatochromism in polar solvents the extent of which could be described by a linear combination of specific and non-specific solute-solvent interactions. The electronic absorption spectrum showed a single band in the UV region (Figure 5a). This band was shifted bathochromically by $13 \mathrm{~nm}$ on changing the solvent from water to dichloromethane (see Experimental Section). The electronic transition leads to less charge separation in the excited state than in the more dipolar ground state, so that increased solvent polarity leads to higher 
transition energy. Transition energies $E_{\mathrm{T}}$ were calculated from the wavelengths of the absorption maxima according to the equation $E_{\mathrm{T}} / \mathrm{kJ} \cdot \mathrm{mol}^{-1}=h c N / \lambda=119625 /(\lambda / \mathrm{nm})$. A linear solvation energy relationship was established by least-squares fitting of the data to the simplified solvatochromic equation $E_{\mathrm{T}}=E_{\mathrm{T} 0}+s \pi^{*}+a \alpha$ involving only the parameters $\pi^{*}[29]$ and $\alpha$ [30] which represent the dipolarity/polarizability and hydrogen-bond donor acidity of the solvent. The hydrogen-bond acceptor parameter $\beta$ [31] did not significantly contribute to the relationship. The coefficients $s$ and $a$ reflect the sensitivity of the solute to these solvent properties. The $\pi^{*}$ and $\alpha$ values were taken from the compilation of Marcus [32]. From the spectral data, the following equation was derived by multiple linear regression (Figure 5b) which describes the solvatochromic behavior of the triazene 3.

$$
E_{\mathrm{T}} / \mathrm{kJ} \cdot \mathrm{mol}^{-1}=323.10+14.20 \pi *+8.72 \alpha\left(n=7, r^{2}=0.985\right)
$$

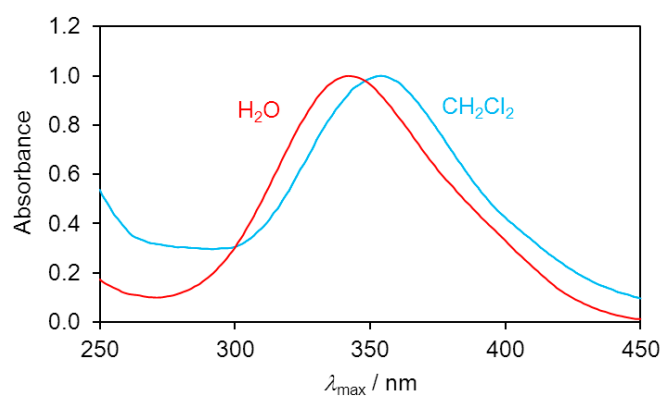

(a)

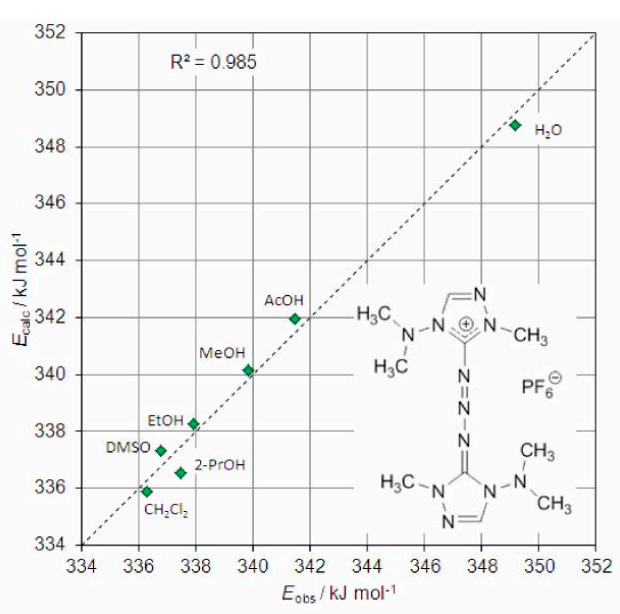

(b)

Figure 5. (a) Normalized UV spectra of triazene 3 in $\mathrm{H}_{2} \mathrm{O}$ and $\mathrm{CH}_{2} \mathrm{Cl}_{2}$; (b) Correlation of observed vs. calculated UV transition energies of triazene 3 in seven polar solvents.

\subsection{Differential Scanning Calorimetry (DSC) and Thermogravimetric Analysis (TGA)}

Thermoanalysis of 1 showed a phase transition at $62^{\circ} \mathrm{C}$. Both compounds $\mathbf{1}$ and 3 exhibited exothermal decomposition at higher temperatures (decomposition maxima at 163 and $210^{\circ} \mathrm{C}$ ) with considerable mass loss (Figure 6). The melting point of compound 2 was unremarkable.

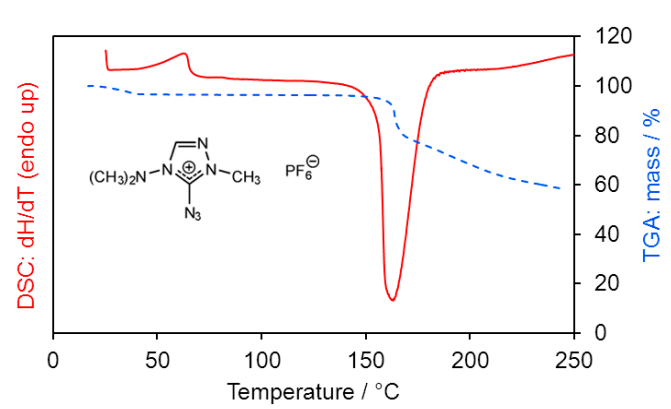

(a)

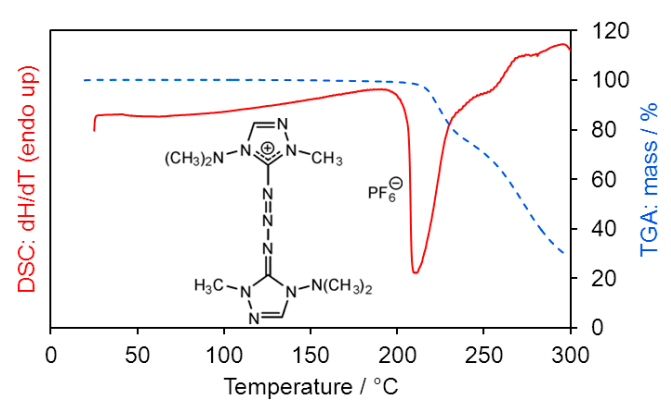

(b)

Figure 6. DSC and TGA (a) of $\mathbf{1}$ and (b) of 3 . Heating rate $10^{\circ} \mathrm{C} \cdot \mathrm{min}^{-1}$.

\section{Experimental Section}

4-(Dimethylamino)-1-methyl-1,2,4-triazolium hexafluoridophosphate and 5-bromo-4-(dimethylamino)-1-methyl-1,2,4-triazolium hexafluoridophosphate were prepared as described previously [33]. 
All other chemicals were purchased from Sigma-Aldrich (European affiliate, Steinheim, Germany). NMR spectra were recorded with a Bruker Avance DPX 300 spectrometer (Billerica, MA, USA). IR spectra were obtained with a Nicolet 5700 FT spectrometer (Thermo Fisher Scientific Inc., Waltham, MA, USA) in ATR mode. UV spectra were recorded with a Perkin-Elmer Lambda XLS+ spectrometer (Waltham, MA, USA); mean values of five replicates were taken. DSC and TGA were recorded with Perkin-Elmer DSC 7 and TGA 7 instruments (Waltham, MA, USA) at a heating rate of $10^{\circ} \mathrm{C} \cdot \mathrm{min}^{-1}$. High-resolution mass spectra were measured with a Finnigan MAT 95 mass spectrometer. In general, spectra were recorded from the crude but pure compounds, not from single-crystalline material. Single crystal diffraction intensity data were recorded by $\omega$ scans with an Oxford Diffraction Gemini-R Ultra (Oxford Diffraction Ltd., Abingdon, Oxfordshire, UK) diffractometer at 173(2) K. Absorption corrections were applied in all cases (multi-scan). The structures were solved by direct methods and refined by full-matrix least-squares techniques on $F^{2}$. CCDC 1444906-1444908 contains the supplementary crystallographic data for this paper. These data can be obtained free of charge via http://www.ccdc.cam.ac.uk/conts/retrieving.html.

\subsection{5-Azido-4-(dimethylamino)-1-methyl-1,2,4-triazolium Hexafluoridophosphate (1)}

Cautionary note: although we did not encounter any difficulties, azides should generally be treated with respect because they are potentially explosive. To a solution of 5-bromo-4-(dimethylamino)-1-methyl-1,2,4-triazolium hexafluoridophosphate (1.00 g, $2.84 \mathrm{mmol})$ in acetone $(20 \mathrm{~mL}), \mathrm{NaN}_{3}(185 \mathrm{mg}, 2.84 \mathrm{mmol})$ was added. The mixture was stirred for $20 \mathrm{~h}$ at room temperature. The precipitate was filtered off, washed with acetone $(5 \mathrm{~mL})$, and the solvent was evaporated at reduced pressure. The residue was washed with $\mathrm{Et}_{2} \mathrm{O}(5 \mathrm{~mL})$ and dried to yield a colorless powder $(0.66 \mathrm{~g}, 74 \%)$. Single crystals were obtained by slow evaporation of a solution in acetone. M.p. $155^{\circ} \mathrm{C}$ (decomposition). ${ }^{1} \mathrm{H}$ NMR (DMSO-d $\left.6,300 \mathrm{MHz}, \delta\right): 2.97(\mathrm{~s}, 6 \mathrm{H}), 3.73(\mathrm{~s}, 3 \mathrm{H})$, $9.65(\mathrm{~s}, 1 \mathrm{H}) \mathrm{ppm} .{ }^{13} \mathrm{C}$ NMR (DMSO-d $\left.6,75 \mathrm{MHz}, \delta\right): 36.2,46.9(2 \mathrm{C}), 139.7(\mathrm{CH}), 144.0$ ppm. ${ }^{1} \mathrm{H}$ NMR (acetone- $\left.\mathrm{d}_{6}, 300 \mathrm{MHz}, \delta\right): 3.17(\mathrm{~s}, 6 \mathrm{H}), 3.83(\mathrm{~s}, 3 \mathrm{H}), 9.39(\mathrm{~s}, 1 \mathrm{H}) \mathrm{ppm} .{ }^{13} \mathrm{C}$ NMR (acetone- $\mathrm{d}_{6}, 75 \mathrm{MHz}, \delta$ ): 37.0, $47.7(2 \mathrm{C}), 140.1(\mathrm{CH}), 145.4 \mathrm{ppm}$. IR (neat) $\widetilde{v}: 3166,2166,1600,823,555 \mathrm{~cm}^{-1}$.

\subsection{5-(3-Azatricyclo[3.2.1.0 $\left.0^{2,4}\right]$ oct-3-yl)-4-(dimethylamino)-1-methyl-1,2,4-triazolium Hexafluorido-Phosphate (2)}

A solution of azide $\mathbf{1}(0.35 \mathrm{~g}, 1.1 \mathrm{mmol})$ and bicyclo[2.2.1]hept-2-ene $(0.12 \mathrm{~g}, 1.3 \mathrm{mmol})$ in acetone $(10 \mathrm{~mL})$ was stirred for $17 \mathrm{~h}$ at room temperature. The volatiles were removed, and the residue was washed with $\mathrm{Et}_{2} \mathrm{O}(3 \times 5 \mathrm{~mL})$ and dried to yield $2(0.28 \mathrm{~g}, 66 \%)$. Single crystals were obtained by diffusion of $\mathrm{Et}_{2} \mathrm{O}$ into a solution in acetone. M.p. $164{ }^{\circ} \mathrm{C} .{ }^{1} \mathrm{H}$ NMR (acetone- $\left.\mathrm{d}_{6}, 300 \mathrm{MHz}, \delta\right): 1.03(\mathrm{~d}$, $J=10.3 \mathrm{~Hz}, 1 \mathrm{H}), 1.36(\mathrm{~m}, 2 \mathrm{H}), 1.52(\mathrm{~d}, J=10.5 \mathrm{~Hz}, 1 \mathrm{H}), 1.62(\mathrm{~d}, J=9.0 \mathrm{~Hz}, 2 \mathrm{H}), 2.76(\mathrm{~s}, 2 \mathrm{H}), 3.03(\mathrm{~s}, 6 \mathrm{H})$, $3.60(\mathrm{~s}, 2 \mathrm{H}), 3.91$ (s, 3H), 9.07 (s, 1H) ppm. ${ }^{13} \mathrm{C} \mathrm{NMR}$ (acetone-d $\left.\mathrm{d}_{6}, 75 \mathrm{MHz}, \delta\right): 26.3(2 \mathrm{C}), 29.3,37.4,37.6$ (2C), $46.1(2 \mathrm{C}), 47.8(2 \mathrm{C}), 138.4(\mathrm{CH}), 152.4 \mathrm{ppm}$. IR (neat) $\tilde{v}: 3150,2972,1600,825,554 \mathrm{~cm}^{-1}$.

\subsection{4-(Dimethylamino)-1-methyl-5-(1-(4-(dimethylamino)-1-methyl-}

1,2,4-triazolin-5-ylidene)triazen-3-yl)-1,2,4-triazolium Hexafluoridophosphate (3)

A $\mathrm{LiN}\left(\mathrm{SiMe}_{3}\right)_{2}$ solution (1M in THF, $\left.0.40 \mathrm{~mL}\right)$ was added to a solution of 4-(dimethylamino)-1-methyl-1,2,4-triazolium hexafluoridophosphate $(0.10 \mathrm{~g}, 0.37 \mathrm{mmol})$ in THF $(5 \mathrm{~mL})$ and stirred at room temperature for $30 \mathrm{~min}$. Then azide $\mathbf{1}(0.12 \mathrm{~g}, 0.38 \mathrm{mmol})$ was added, and the mixture was stirred at room temperature for $30 \mathrm{~h}$. The precipitate was filtered off and dried to yield a yellow powder $(25 \mathrm{mg}, 15 \%)$. Single crystals were obtained by slow evaporation of a solution in acetone. M.p. $203{ }^{\circ} \mathrm{C}$ (decomposition). ${ }^{1} \mathrm{H}$ NMR (acetone- $\left.\mathrm{d}_{6}, 300 \mathrm{MHz}, \delta\right): 3.10(\mathrm{~s}, 6 \mathrm{H}), 4.04(\mathrm{~s}, 3 \mathrm{H})$, $9.04(\mathrm{~s}, 1 \mathrm{H}) \mathrm{ppm} .{ }^{13} \mathrm{C}$ NMR (acetone-d $\mathrm{d}_{6}, 75 \mathrm{MHz}, \delta$ ): 39.6, 47.0 (2C), 140.7, $153.6 \mathrm{ppm}$. IR (neat) $\widetilde{v}: 3159$, 1537, 1446, 1276, 1250, 1183, 1156, 832, 724, $554 \mathrm{~cm}^{-1}$. HRMS (ES): $\mathrm{m} / z=294.1893$ (calcd. 294.1898 for $\left.\mathrm{C}_{10} \mathrm{H}_{20} \mathrm{~N}_{11},[\mathrm{M}]^{+}\right)$. UV (solvent): $\lambda_{\max } 342.6\left(\mathrm{H}_{2} \mathrm{O}\right), 350.3(\mathrm{AcOH}), 352.0(\mathrm{MeOH}), 354.0(\mathrm{EtOH}), 354.5$ (2-PrOH), 355.2 (DMSO), $355.8\left(\mathrm{CH}_{2} \mathrm{Cl}_{2}\right) \mathrm{nm}$. 


\subsection{4-(Dimethylamino)-1-methyl-5-amino-1,2,4-triazolium Hexafluoridophosphate (4)}

A solution of azide $\mathbf{1}(0.10 \mathrm{~g}, 0.32 \mathrm{mmol})$ and triphenylphosphane $(84 \mathrm{mg}, 0.32 \mathrm{mmol})$ in acetone $(3 \mathrm{~mL})$ was stirred for $5 \mathrm{~h}$ at room temperature. The volatiles were removed, and the residue was partitioned between $\mathrm{H}_{2} \mathrm{O}(2 \mathrm{~mL})$ and $\mathrm{CH}_{2} \mathrm{Cl}_{2}(2 \times 1 \mathrm{~mL})$. The aqueous phase was dried to yield 4 (50 mg, 29\%). ${ }^{1} \mathrm{H}$ NMR (acetone- $\left.\mathrm{d}_{6}, 300 \mathrm{MHz}, \delta\right): 2.97$ (s, 6H), $3.82(\mathrm{~s}, 3 \mathrm{H}), 8.94(\mathrm{~s}, 1 \mathrm{H}) \mathrm{ppm} .{ }^{13} \mathrm{C}$ NMR (acetone- $\mathrm{d}_{6}, 75 \mathrm{MHz}, \delta$ ): 36.0, 47.1 (2C), 136.3, 149.5 ppm. IR (neat) $\widetilde{v}: 3476,3162,1686,1261,824$, $556 \mathrm{~cm}^{-1}$. MS (ES): $m / z=142.111$ (calcd. 142.109 for $\mathrm{C}_{5} \mathrm{H}_{12} \mathrm{~N}_{5},[\mathrm{M}]^{+}$).

\section{Conclusions}

Nitrogen-rich azidoazolium salts are not only of interest as structural motifs in the area of energetic materials but also represent valuable intermediates in synthetic chemistry. The versatility of azide chemistry definitely contributes to the increasing popularity of this functional group in the field of heterocyclic chemistry.

Acknowledgments: The authors are grateful to E. Gstrein and Ulrich J. Griesser for the measurement of DSC and TGA.

Author Contributions: Gerhard Laus and Herwig Schottenberger conceived and designed this study. Gerhard Laus carried out experimental work (synthesis, crystallization and characterization) and wrote the manuscript. Volker Kahlenberg determined the crystal structures.

Conflicts of Interest: The authors declare no conflict of interest.

\section{References}

1. Hammerl, A.; Klapötke, T.M.; Mayer, P.; Weigand, J.J. Synthesis, structure, molecular orbital calculations and decomposition mechanism for tetrazolylazide $\mathrm{CHN}_{7}$, its phenyl derivative $\mathrm{PhCN}_{7}$ and tetrazolylpentazole $\mathrm{CHN}_{9}$. Propellants Explos. Pyrotech. 2005, 30, 17-26. [CrossRef]

2. Klapötke, T.M.; Stierstorfer, J. The $\mathrm{CN}_{7}{ }^{-}$anion. J. Am. Chem. Soc. 2009, 131, 1122-1134. [CrossRef] [PubMed]

3. Stierstorfer, J.; Klapötke, T.M.; Hammerl, A.; Chapman, R.D. 5-Azido-1H-tetrazole-Improved synthesis, crystal structure and sensitivity data. Z. Anorg. Allg. Chem. 2008, 634, 1051-1057. [CrossRef]

4. Izsák, D.; Klapötke, T.M. Preparation and crystal structure of 5-Azido-3-nitro-1H-1,2,4-triazole, Its methyl derivative and potassium salt. Crystals 2012, 2, 294-305. [CrossRef]

5. Qi, C.; Li, S.H.; Li, Y.C.; Wang, Y.; Zhao, X.X.; Pang, S.P. Synthesis and promising properties of a new family of high-nitrogen compounds: Polyazido- and polyamino-substituted N,N'-Azo-1,2,4-triazoles. Chem. Eur. J. 2012, 18, 16562-16570. [CrossRef] [PubMed]

6. Izsák, D.; Klapötke, T.M.; Reuter, S.; Rösener, T. Silver salt and derivatives of 5-Azido-1H-1,2,4triazole-3-carbonitrile. Z. Anorg. Allg. Chem. 2013, 639, 899-905. [CrossRef]

7. Balli, H.; Maul, R. Azidiniumsalze und Triazatrimethincyanine substituierter Benzimidazole. Helv. Chim. Acta 1976, 59, 148-155. (In German). [CrossRef]

8. Balli, H.; Löw, R. Azidiniumsalze und Triazatrimethincyanine substituierter Thiazole. Helv. Chim. Acta 1976, 59, 155-164. (In German). [CrossRef]

9. Lehmann, U.; Balli, H. Ansa-triazacarbocyanine der [n](1,3)-benzimidazolophan-reihe: Synthese, spektroskopische untersuchungen und photochemische eigenschaften. Dyes Pigment. 1983, 4, 121-161. (In German). [CrossRef]

10. Xue, H.; Gao, Y.; Twamley, B.; Shreeve, J.M. New energetic salts based on nitrogen-containing heterocycles. Chem. Mater. 2005, 17, 191-198. [CrossRef]

11. Laus, G.; Schwärzler, A.; Schuster, P.; Bentivoglio, G.; Hummel, M.; Wurst, K.; Kahlenberg, V.; Lörting, T.; Schütz, J.; Peringer, P.; et al. $N, N^{\prime}$-Di(alkyloxy)imidazolium salts: new patent-free ionic liquids and NHC precatalysts. Z. Naturforsch. 2007, 62, 295-308. [CrossRef]

12. Kitamura, M.; Kato, S.; Yano, M.; Tashiro, N.; Shiratake, Y.; Sando, M.; Okauchi, T. A reagent for safe and efficient diazo-transfer to primary amines: 2-azido-1,3-dimethylimidazolinium hexafluorophosphate. Org. Biomol. Chem. 2014, 12, 4397-4406. [CrossRef] [PubMed] 
13. Khramov, D.M.; Bielawski, C.W. Triazene formation via reaction of imidazol-2-ylidenes with azides. Chem. Commun. 2005, 4958-4960. [CrossRef] [PubMed]

14. Khramov, D.M.; Bielawski, C.W. Donor-acceptor triazenes: Synthesis, characterization, and study of their electronic and thermal properties. J. Org. Chem. 2007, 72, 9407-9417. [CrossRef] [PubMed]

15. Patil, S.; Bugarin, A. Crystal structure of (E)-1,3-dimethyl-2-[3-(3-nitrophenyl)-triaz-2-en-1-ylidene] -2,3-dihydro-1H-imidazole. Acta Crystallogr. 2014, 70, 224-227. [CrossRef] [PubMed]

16. Kunetskiy, R.A.; Cisarova, I.; Saman, D.; Lyapkalo, I.M. New lipophilic 2-Amino- $N, N^{\prime}-$ dialkyl-4,5-dimethylimidazolium cations: Synthesis, structure, properties, and outstanding thermal stability in alkaline media. Chem. Eur. J. 2009, 15, 9477-9485. [CrossRef] [PubMed]

17. Lysenko, S.; Daniliuc, C.G.; Jones, P.G.; Tamm, M. Tungsten alkylidyne complexes with ancillary imidazolin-2-iminato and imidazolidin-2-iminato ligands and their use in catalytic alkyne metathesis. J. Organomet. Chem. 2013, 744, 7-14. [CrossRef]

18. Tennyson, A.G.; Moorhead, E.J.; Madison, B.L.; Er, J.A.V.; Lynch, V.M.; Bielawski, C.W. Methylation of ylidene-triazenes: Insight and guidance for 1,3-dipolar cycloaddition reactions. Eur. J. Org. Chem. 2010, 6277-6282. [CrossRef]

19. Patil, S.; White, K.; Bugarin, A. Novel triazene dyes from N-heterocyclic carbenes and azides: Syntheses, stability, and spectroscopic properties. Tetrahedron Lett. 2014, 55, 4826-4829. [CrossRef]

20. Patil, S.; Bugarin, A. Fifty years of $\pi$-conjugated triazenes. Eur. J. Org. Chem. 2015. [CrossRef]

21. Naef, R.; Balli, H. Synthesis, structure and photochemical properties of 4,4',7,7'-tetra-substituted 1,1',3,3'-tetraethylbenzimidazolotriazatrimethine cyanines. Helv. Chim. Acta 1978, 61, 2958-2973. [CrossRef]

22. Bräse, S.; Gil, C.; Knepper, K.; Zimmermann, V. Organic azides: An Exploding diversity of a unique class of compounds. Angew. Chem. Int. Ed. 2005, 44, 5188-5240. [CrossRef] [PubMed]

23. Henery-Logan, K.R.; Clark, R.A. The reaction of phenyl azide with olefins. Tetrahedron Lett. 1968, 9, 801-806. [CrossRef]

24. Alder, K.; Stein, G. Über das abgestufte Additionsvermögen von ungesättigten Ringsystemen. Justus Liebigs Ann. Chem. 1933, 501, 1-48. (In German). [CrossRef]

25. Scheiner, P.; Schomaker, J.H.; Deming, S.; Libbey, W.J.; Nowack, G.P. The addition of aryl azides to norbornene. A kinetic investigation. J. Am. Chem. Soc. 1965, 87, 306-311. [CrossRef]

26. Haslinger, S.; Laus, G.; Wurst, K.; Schottenberger, H. Crystal structure of 1-(1-methyl-1H-imidazol-2-yl) -4-phenyl-1H-1,2,3-triazole dihydrate. Acta Cryst. 2015, 71, o945-o946. [CrossRef]

27. Chopra, D.; Guru Row, T.N. Role of organic fluorine in crystal engineering. CrystEngComm 2011, 13, 2175-2186. [CrossRef]

28. D'Oria, E.; Novoa, J.J. On the hydrogen bond nature of the C-H...F interactions in molecular crystals. An exhaustive investigation combining a crystallographic database search and ab initio theoretical calculations. CrystEngComm 2008, 10, 423-436. [CrossRef]

29. Kamlet, M.J.; Abboud, J.L.M.; Taft, R.W. The solvatochromic comparison method. The $\pi^{*}$ scale of solvent polarities. J. Am. Chem. Soc. 1977, 99, 6027-6038. [CrossRef]

30. Taft, R.W.; Kamlet, M.J. The solvatochromic comparison method. The $\alpha$ scale of solvent hydrogen-bond donor (HBD) acidities. J. Am. Chem. Soc. 1976, 98, 2886-2894. [CrossRef]

31. Kamlet, M.J.; Taft, R.W. The solvatochromic comparison method. The $\beta$ scale of solvent hydrogen-bond acceptor (HBA) basicities. J. Am. Chem. Soc. 1976, 98, 377-383. [CrossRef]

32. Marcus, $Y$. The properties of organic liquids that are relevant to their use as solvating solvents. Chem. Soc. Rev. 1993, 409-416. [CrossRef]

33. Schwärzler, A.; Laus, G.; Kahlenberg, V.; Wurst, K.; Gelbrich, T.; Kreutz, C.; Kopacka, H.; Bonn, G.; Schottenberger, H. Quaternary 4-amino-1,2,4-triazolium salts: Crystal structures of ionic liquids and N-heterocyclic carbene (NHC) complexes. Z. Naturforsch. 2009, 64, 603-616. [CrossRef]

(C) 2016 by the authors; licensee MDPI, Basel, Switzerland. This article is an open access article distributed under the terms and conditions of the Creative Commons by Attribution (CC-BY) license (http://creativecommons.org/licenses/by/4.0/). 